\title{
Neuronal Migration Depends on Intact Peroxisomal Function in Brain and in Extraneuronal Tissues
}

\author{
Anneleen Janssen, ${ }^{1}$ Pierre Gressens, ${ }^{3}$ Markus Grabenbauer, ${ }^{4}$ Eveline Baumgart, ${ }^{4}$ Arno Schad, ${ }^{4}$ Ilse Vanhorebeek, ${ }^{1}$ \\ Annelies Brouwers, ${ }^{1}$ Peter E. Declercq, ${ }^{1}$ Dariush Fahimi, ${ }^{4}$ Philippe Evrard, ${ }^{3}$ Luc Schoonjans, ${ }^{5}$ Désiré Collen, ${ }^{6}$ \\ Peter Carmeliet, ${ }^{6}$ Guy Mannaerts, ${ }^{2}$ Paul Van Veldhoven, ${ }^{2}$ and Myriam Baes ${ }^{1}$ \\ ${ }^{1}$ Laboratory of Clinical Chemistry and ${ }^{2}$ Department of Pharmacology, K. U. Leuven, 3000 Leuven, Belgium, ${ }^{3}$ Laboratory of Developmental Neurology, \\ Hospital Robert-Debré, 75019 Paris, France, ${ }^{4}$ Department of Anatomy and Cell Biology II, University of Heidelberg, 69117 Heidelberg, Germany, ${ }^{5}$ Thromb- \\ $\mathrm{X}, 3000$ Leuven, Belgium, and ${ }^{6}$ Center for Transgene Technology and Gene Therapy, Flanders Interuniversity Institute for Biotechnology, 3000 Leuven, \\ Belgium
}

Functional peroxisome deficiency, as encountered in Zellweger syndrome, causes a specific impairment of neuronal migration. Although the molecular mechanisms underlying the neuronal migration defect are at present unknown, the excess of very long chain fatty acids in brain, a consequence of peroxisomal $\beta$-oxidation deficiency, has often been hypothesized to play a major role. The purpose of the present study was to investigate the contribution of peroxisomal dysfunction in brain as opposed to peroxisomal dysfunction in extraneuronal tissues to the migration defect. Peroxisomes were selectively reconstituted either in brain or liver of Pex5 knock-out mice, a model for Zellweger syndrome, by tissue-selective overexpression of Pex $5 \mathrm{p}$. We found that both rescue strains exhibited a significant correction of the neuronal migration defect despite an incomplete reconstitution of peroxisomal function in the targeted tissue. Animals with a simultaneous rescue of peroxisomes in both tissues displayed a pattern of neuronal migration indistinguishable from that of wild-type animals on the basis of cresyl violet staining and $5^{\prime}, 3^{\prime}$-bromo- $2^{\prime}$-deoxyuridine birth-dating analysis. These data suggest that peroxisomal metabolism in brain but also in extraneuronal tissues affects the normal development of the mouse neocortex. In liver-rescued mice, the improvement of the neuronal migration was not accompanied by changes in very long chain fatty acid, docosahexaenoic acid, or plasmalogen levels in brain, indicating that other metabolic factors can influence the neuronal migration process.

Key words: neuronal migration; peroxisome; Zellweger syndrome; VLCFA; plasmalogen; DHA

\section{Introduction}

The laminar organization of neocortex depends on the radial migration of numerous neurons from the subventricular zone toward the surface using radial glial cells as a scaffold (Hatten, 1999; Gressens, 2000). Although the molecular mechanisms controlling the migration process are not fully understood, recent studies have implicated a number of neuronal and glial ligandreceptor systems and cytoskeleton-interacting proteins in this directed migration, including adhesion molecules, extracellular matrix proteins, cell surface receptors, neurotransmitters, and calcium influx (Komuro and Rakic, 1992; Rakic et al., 1994; Behar et al., 1996; Walsh, 1999).

Received May 1, 2003; revised Aug. 14, 2003; accepted Aug. 28, 2003.

This work was funded by European Community Grant Biomed BMH4-98-3569, European Commission Grant QLG1-CT2001-01277, Fonds Wetenschappelijk Onderzock Vlaanderen Grant G.0280.97, and Geconcerteerde Onderzocksacties Grant 99/09. A.J. was an IWT fellow. We thank Dr. R. McKay [National Institutes of Health (NIH), Bethesda, MD], Dr. M. Brenner (NIH), and Dr. S. Tilghman (Princeton University, Princeton, NJ) for providing plasmids, Dr. S. Subramani (University of California, San Diego, CA) and Dr. G. Dodt ( Ruhr University, Bochum, Germany) for providing antisera, and L. Kiekens, S. Danloy, V. Kreemers, E. Meyhi, B. Das, L. Pauwels, I. Frommer, and G. Krämer for technical help.

Correspondence should be addressed to Dr. Myriam Baes, Laboratory of Clinical Chemistry, K. U. Leuven, Herestraat 49, Onderwijs and Navorsing, B-3000 Leuven, Belgium. E-mail: myriam.baes@pharm.kuleuven.ac.be.

E. Baumgart's present address: Institute for Anatomy and Cell Biology, University of Giessen, 35390 Giessen, Germany.

Copyright $\odot 2003$ Society for Neuroscience $\quad 0270-6474 / 03 / 239732-10 \$ 15.00 / 0$
Much less attention has been paid to metabolic factors controlling neuronal migration. Nonetheless, it is well known that peroxisome deficiency, as encountered in the rare inherited syndrome of Zellweger, is associated with a very characteristic impairment of neuronal migration (Evrard et al., 1978), resulting in gyral abnormalities of the cerebral cortex and heterotopias in neocortex, cerebellum, and inferior olivary complex. Patients suffering from Zellweger syndrome present with extreme hypotonia, neonatal seizures, and severe mental retardation and die usually within the first year of life. Zellweger syndrome is the prototype and most severe form of the peroxisome biogenesis disorders, a heterogeneous group of autosomal recessive diseases caused by the defective import of peroxisomal matrix or membrane proteins (Subramani et al., 2000; Terlecky and Fransen, 2000; Gould et al., 2001; Purdue and Lazarow, 2001). The defective import of peroxisomal proteins results in the loss of multiple peroxisomal functions attributable to inactivity of most unimported enzymes in the cytosol. The major metabolic consequences include increased levels of very long chain fatty acids (VLCFAs), bile acid intermediates, and 2- and 3-methylbranched chain fatty acids, a depletion of ether phospholipids, including plasmalogens and platelet-activating factor, and reduced levels of the polyunsaturated fatty acid docosahexaenoic acid (DHA, C22:6n-3). Despite extensive knowledge of the met- 
abolic role of peroxisomes, to date it remains unclarified how defective peroxisomal function influences neuronal mobility during the migration process (Powers, 1995).

Animal models of peroxisome biogenesis disorders have been generated by targeted inactivation of either the Pex 5 gene (Baes et al., 1997), encoding the import receptor for most peroxisomal matrix proteins, or the Pex2 gene (Faust and Hatten, 1997), encoding a peroxisomal membrane protein. Both knock-out mouse models displayed intrauterine growth retardation, were severely hypotonic at birth, died within $72 \mathrm{hr}$, and exhibited the known metabolic abnormalities of Zellweger patients.

Neurodevelopmental analysis of peroxisome-deficient fetuses revealed a neuronal migration defect in neocortex, a delay in neuronal maturation, significantly increased apoptosis in the cortical plate, and structural abnormalities in the inferior olivary nucleus, all typical of Zellweger syndrome (Baes et al., 1997; Faust and Hatten, 1997).

The purpose of the present study was to investigate the contribution of peroxisomal dysfunction in brain as opposed to peroxisomal dysfunction in extraneuronal tissues to the neuronal migration impairment in Pex5 knock-out mice. To this end, transgenic mice were generated with selective expression of peroxisomes in either brain or liver, an organ with abundant peroxisomes, by tissue-selective overexpression of the Pex 5 protein (Pex5p) in the knock-out mice.

\section{Materials and Methods}

Transgenic DNA constructs

The full-length coding region of the long form of mouse Pex 5 cDNA was generated by reverse transcription (RT)-PCR using Expand reverse transcriptase (Roche, Brussels, Belgium) on mouse liver RNA and Expand high-fidelity PCR enzyme mix (Roche) using the primers 5'-TACTACGGCGCGCCATGGCAATGCGGGAGCTGGTGGAG-3' (forward) and 5'-GTGGTGTCTAGATCACTGGGGCAGGCCAAACATAGC-3' (reverse). The Pex5L cDNA and the myc9E10 epitope preceded by the Kozak consensus sequence were subcloned in a modified $p N E B$ vector (New England Biolabs, Leusden, The Netherlands).

For the brain-selective reconstitution of Pex5p, the nestin second intron was subcloned from the p401ZgII plasmid provided by Dr. R. McKay [National Institutes of Health (NIH), Bethesda, MD] (Zimmerman et al., 1994). The thymidine kinase (TK) minimal promoter was amplified by PCR, and the $0.6 \mathrm{~kb}$ mouse protamine 1 gene $(\mathrm{mP} 1)$ segment containing an intron, a $3^{\prime}$ untranslated region and, a polyadenylation signal was taken from the $p G f a 2 l a c-1$ plasmid obtained from Dr. M. Brenner (NIH). On both sides of the nestin/TK-mycPex5-mp1 construct, an 800 bp insulator sequence was subcloned, derived from the human $\beta$-globin 3'-DNase I-hypersensitive site (Fleenor and Kaufman, 1993), and obtained by PCR on HeLa cell genomic DNA.

For the liver-selective reconstitution of Pex $5 \mathrm{p}$, the $7.6 \mathrm{~kb} 5^{\prime}$ flanking region of the $\alpha$-fetoprotein (AFP) gene (Godbout et al., 1986; Hammer et al., 1987) was subcloned from the $P A F P$ vector provided by S. Tilghman (Princeton University, Princeton, NJ). The AFP-mycPex5-mP1 construct was inserted into the pLA39 vector in between two identical insulator sequences, each consisting of two copies of a $1.2 \mathrm{~kb}$ fragment of the chicken $\beta$-globin gene (Pikaart et al., 1998; Potts et al., 2000).

More details on the assembly of the vectors destined for the brain- or liver-selective overexpression of Pex5p are available on request. A diagram of these constructs is shown in Figure 1.

Generation, identification, and breeding of transgenic mice The nestin-TK-mycPex5 transgene was liberated by PacI digestion, whereas the plasmid containing the AFP-mycPex5 transgene was linearized with $P v u I$. Transgenes were gel-purified, diluted to a final concentration of $5 \mathrm{ng} / \mu \mathrm{l}$, and used for microinjection into the male pronucleus of fertilized eggs of the FVB/N strain. The incorporation of the transgene was examined in 3-week-old mice by Southern blot analysis of tail DNA using BamHI digestion and a 5' genomic Pex5 probe, previously devel-
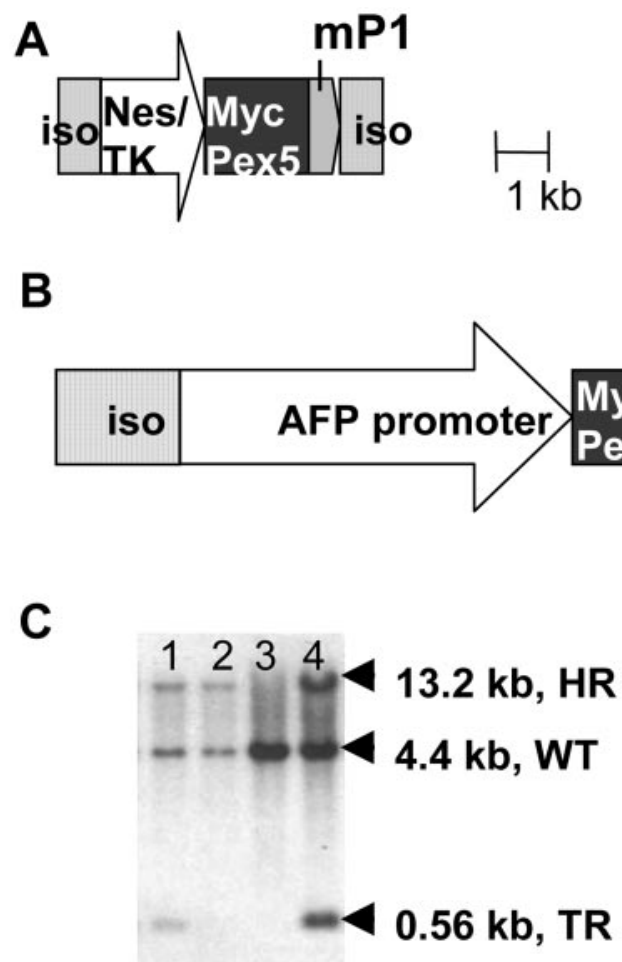

Figure 1. Transgene constructs and identification of Pex5 rescue mice. $A, B$, Diagrams of the transgene constructs designed for brain- and liver-selective expression of mycPex $5 p$, respectively. iso, Isolator; Nes/TK, nestin second intron fused to thymidine kinase promoter. C, Southern blot analysis of BamHI-digested tail DNA identifying the wild-type (WT) and recombinant (HR) Pex 5 allele as well as the inserted transgene (TR). Lanes 1, 4, Genomic DNA of LR:Pex $5^{+/-}$

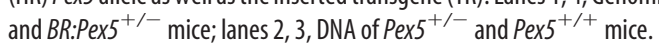

oped to distinguish the wild-type from the recombinant allele in $P e x 5^{+/-}$ mice (Baes et al., 1997) (Fig. 1C). Alternatively, PCR analysis was performed to demonstrate the transgene using as forward primers $5^{\prime}$ CTCACTGAAGGTTACTAGTTAACAGGC-3' (AFP promoter) and 5' TACTACAAGCTTGGCCCCGCCCAGCGTCTT-3' (TK promoter) and the previously mentioned Pex 5 reverse primer. On the basis of Southern blot analysis, it was estimated that the copy number of the inserted transgene was 10 copies in the nestin-TK-mycPex5 transgenic line and two copies in the $A F P-m y c P e x 5$ transgenic line. Founder mice were crossed with $P$ ex $5^{+/-}$mice (inbred in the Tac:[Sw]fBR strain), and the nestinPex5:Pex5 $5^{+/-}$mice identified in the offspring were again mated with $P e x 5^{+/-}$mice to generate nestin-Pex5:Pex5 ${ }^{-1-}$ mice (further denoted $B R: P e x 5^{-/-}$mice, for brain-rescued Pex5 knock-out mice). In a similar

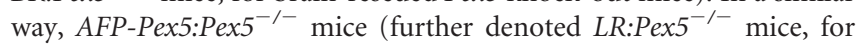
liver-rescued Pex5 knock-out mice) were obtained. In this breeding scheme, the rescue mice and $P e x 5^{-1-}$ mice are generated at an equal frequency (one per eight) allowing the direct comparison of their phenotypes. LR:Pex $5^{+/-}$and $B R: P e x 5^{+/-}$mice were further intercrossed to obtain double-rescue mice denoted LBR:Pex $5^{-1-}$ mice (for liver- and brain-rescued Pex5 knock-out mice). $P e x 5^{+/+}$or $P e x 5^{+/-}$littermates with or without transgene incorporation were used as controls in all studies. Pregnancies were staged as $0.5 \mathrm{~d}$ at $12 \mathrm{PM}$ after detection of a vaginal plug.

The mice were bred in the animal housing facility of the University of Leuven under conventional conditions. They had unlimited access to standard rodent food chow and water and were kept on a $12 \mathrm{hr}$ light/dark cycle. All animal experiments were approved by the Institutional Animal Ethical Committee of the University of Leuven.

\section{Biochemical analysis}

For biochemical analysis of mouse fetuses [embryonic day 14.5 (E14.5) and E18.5], pregnant females were killed by cervical dislocation; the fe- 
tuses were removed; and tissues were immediately frozen in liquid nitrogen.

RNA analysis. RNA extraction from tissues (20-100 $\mathrm{mg})$ and Northern blot analysis were performed as previously described (Huyghe et al., 2001). To remove residual genomic DNA for the evaluation of transgene expression by RT-PCR, $10 \mu \mathrm{g}$ of total RNA was treated for 15 min with $20 \mathrm{U}$ of DNase I (Roche) at $37^{\circ} \mathrm{C}$ in a buffer consisting of (in mM): 25 Tris- $\mathrm{HCl}, \mathrm{pH} 8.3$, $75 \mathrm{KCl}$, and $3 \mathrm{MgCl}_{2}$. Superscript reverse transcriptase (Invitrogen, Merelbeke, Belgium) and $0.5 \mu \mathrm{g}$ of oligo- $\mathrm{dT}_{12-18}$ was used to generate cDNA, followed by PCR with the Pex5 forward and reverse primers previously mentioned.

Western blot analysis. Western blot analysis on homogenates from entire liver, brain, or neocortex was performed as previously described (Huyghe et al., 2001). Rabbit polyclonal antibodies directed to the human Pex5p (a gift from G. Dodt, Ruhr University, Bochum, Germany), the $52 \mathrm{kDa}$ subunit of the rat acyl-CoA oxidase (Van Veldhoven et al., 1994), and the $41 \mathrm{kDa}$ rat 3-ketoacyl-CoA thiolase (Antonenkov et al., 1997) were used.

Determination of dihydroxyacetonephosphate acyl transferase activity. Twenty five microliters of tissue homogenate $(1: 5, \mathrm{w} / \mathrm{v})$ prepared in 5 $\mathrm{mm}$ 4-morpholinepropanesulfonic acid, $\mathrm{pH}$ 7.2, $1 \mathrm{~mm}$ EDTA, and $0.25 \mathrm{~m}$ sucrose were used in the assay previously described (Jones and Hajra, 1994).

Determination of hexacosanoic acid, C22: $6 n-3$, and plasmalogen levels. These lipids were quantified according to previously published protocols (Janssen et al., 2000).

\section{Analysis of peroxisomes}

Electron microscopic analysis of peroxisomes in liver. For the electron microscopic analysis of liver, newborn mice were perfused transcardially with $4 \%(\mathrm{w} / \mathrm{v})$ depolymerized paraformaldehyde and $0.05 \%(\mathrm{v} / \mathrm{v})$ glutaraldehyde in $1 \times$ PBS, $\mathrm{pH} 7.4$, and $2 \%(\mathrm{w} / \mathrm{v})$ sucrose. For detection of peroxisomes, the peroxidatic activity of catalase was demonstrated by the alkaline $3,3^{\prime}$ diaminobenzidine procedure (Fahimi, 1969) with subsequent postfixation in reduced osmium and Epon 812 embedding.

Immunocytochemical and immunohistochemical analysis of peroxisomes in brain. Fetuses were removed and immersion-fixed (E14.5) or perfused intracardially (E18.5) with $4 \%$ freshly depolymerized paraformaldehyde in PBS, pH 7.4, and embedded in paraffin. For immunofluorescent detection of catalase, the antigen retrieval process consisted of treatment with $0.1 \%$ trypsin for $5 \mathrm{~min}$, followed by $15 \mathrm{~min}$ of microwaving $(850 \mathrm{~W})$ in citrate buffer, $\mathrm{pH} 6$ (Grabenbauer et al., 2001). After incubation with a monospecific antibody to catalase (Baumgart et al., 1989) the antigen-binding sites were detected by an Alexa 488-conjugated secondary antibody (Molecular Probes, Eugene, OR). The nuclei were counterstained with propidium iodide, and the sections of neocortex were analyzed by a confocal laser scanning microscope (CLSM; Leica, Heidelberg, Germany). MycPex5p expression was detected by anti-Pex5p (antibody provided by G. Dodt) or anti-myc immunohistochemistry (antibody pro-

C

E18.5

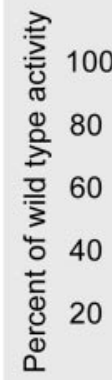

\section{BR:Pex 5\%- mice}
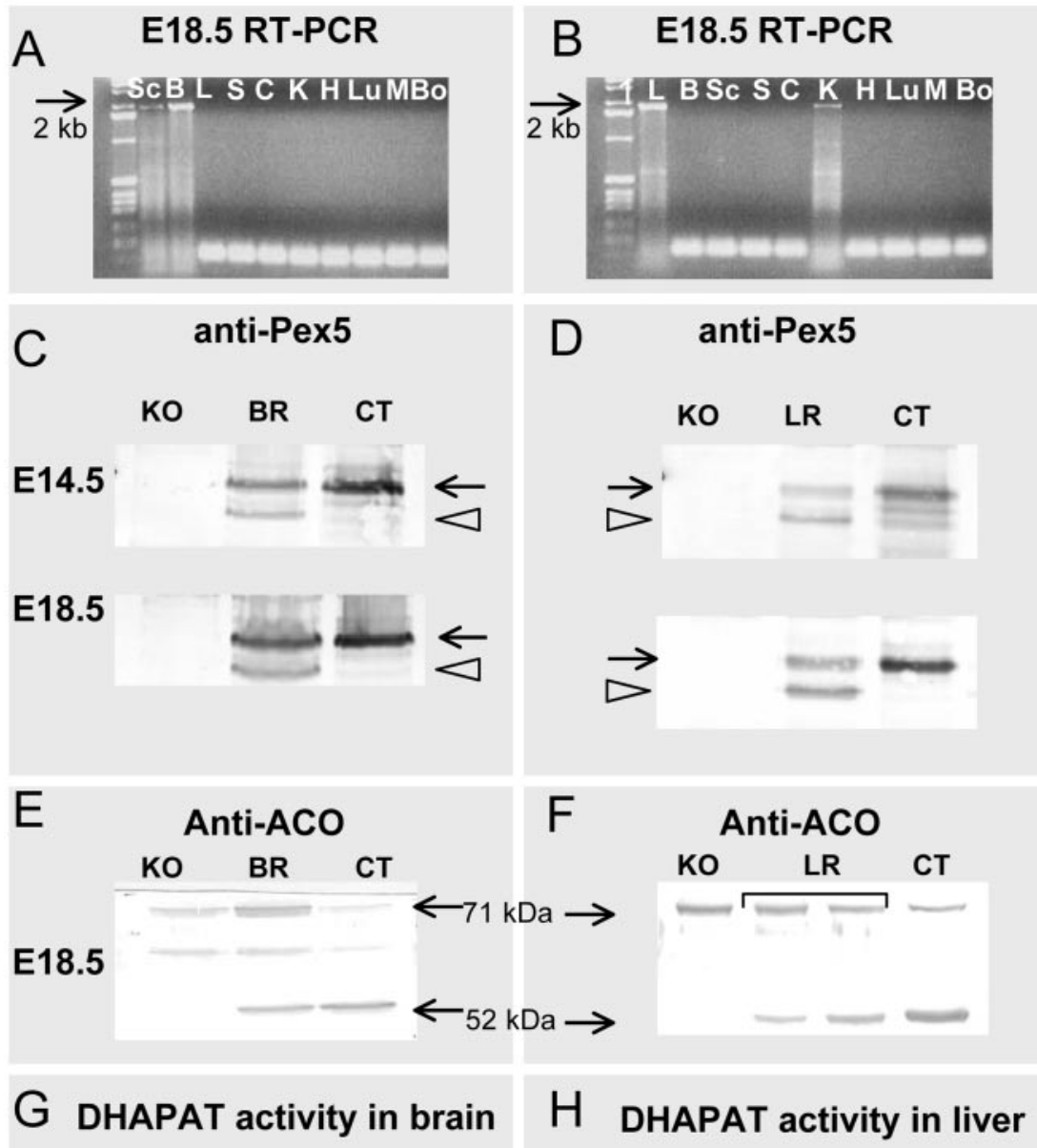

Figure 2. Selectivity and functionality of mycPex5 transgene expression. Analyses of $B R: P e \times 5^{-1-}$ mice are shown on the left analyses of $L R: P e x 5^{-1-}$ mice are shown on the right. $A, B, R T-P C R$ analysis of the indicated tissues derived from E18.5 Pex5 rescue mice. Sc, Spinal cord; B, brain; L, liver; S, stomach; $C$, colon; K, kidney; $H$, heart; Lu, lung; $M$, skeletal muscle; Bo, bone. C, D, Immunoblots of brain (E14.5; $)$, neocortex (E18.5; $)$, and liver homogenates (E14.5, E18.5; $D)$ using an antibody specific for Pex $5 \mathrm{p}$. The full-length protein is indicated by an arrow; a shorter form appearing in the rescue tissues is indicated by an arrowhead. KO, Knock-out; CT, control. E, F, Immunoblots of neocortex $(E 18.5 ; E)$ and liver homogenates (E18.5; $F)$ using an antibody specific for the $52 \mathrm{kDa}$ subunit of ACO. The positions of the unprocessed $71 \mathrm{kDa}$ and the processed $52 \mathrm{kDa}$ bands are indicated. $G, H$, Restoration of DHAPAT activity in brain and liver of E14.5 and E18.5 Pex5 rescue mice. Values are expressed as percentages of activities in control mice of the same age. 


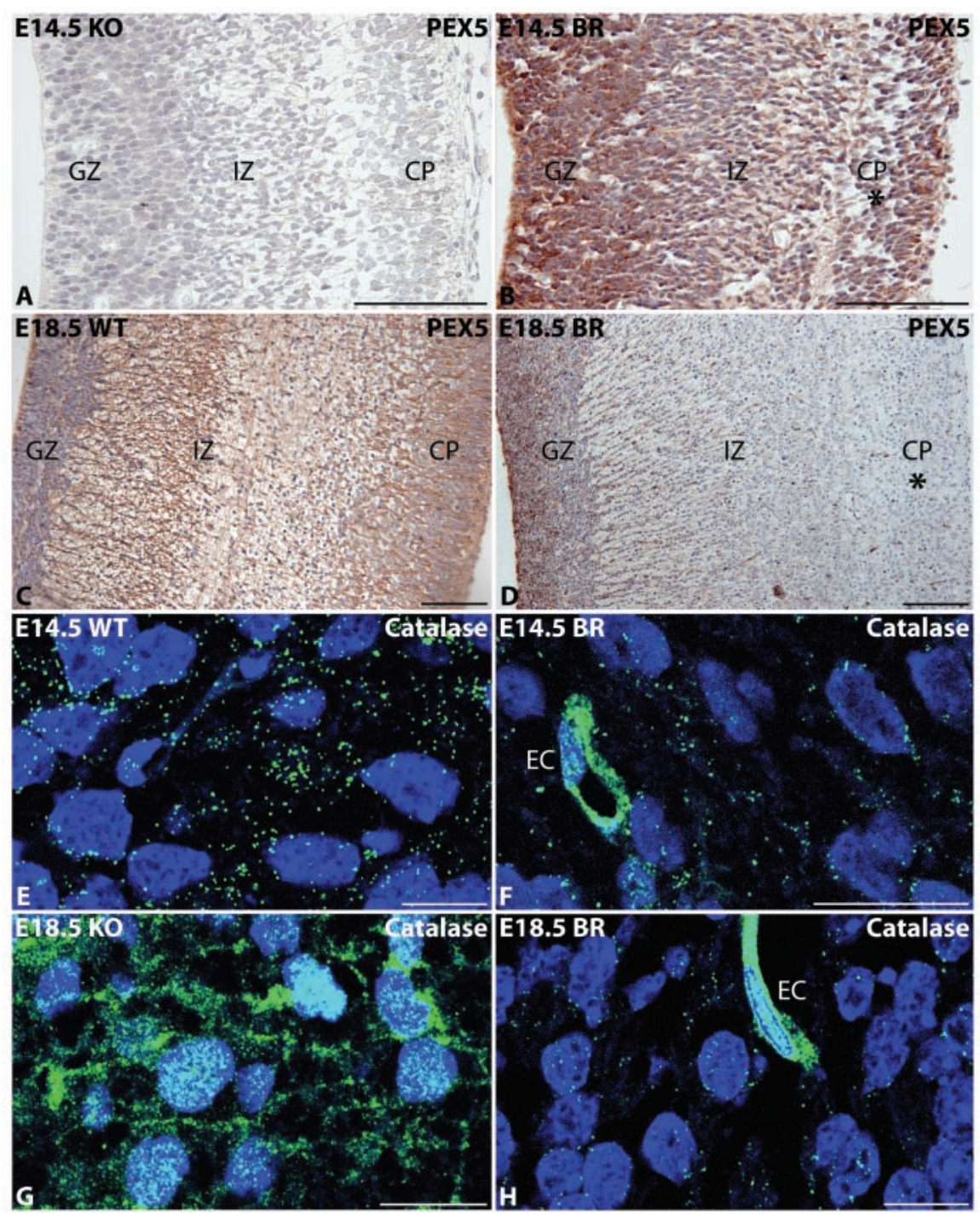

Figure 3. Reconstitution of peroxisomes in the cortex. $A-D$, Immunohistochemical detection of the mycPex 5 fusion protein using a Pex $5 p$ antibody. Pex $5 p$ is not detectable in neocortex of E14.5 knock-out mice $(A)$ but is strongly expressed in E14.5 $(B)$ Pex5 BR mice. Pex5 staining, expressed strongly in all layers of E18.5 wild-type mice $(C)$, is markedly diminished in the outer

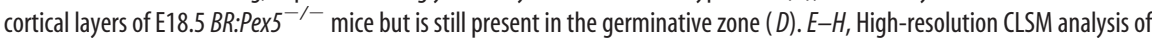
catalase distribution in E14.5 and E18.5 neocortex. The selected neocortex areas for CLSM analysis are marked by asterisks in $B$ and $D$. In all cells of wild-type (WT) mice (E), catalase is present in a punctate pattern (green dots), representing peroxisomes. In Pex5 knock-out mice $(G)$, immunofluorescent detection of catalase results in diffuse green fluorescent staining in the cytoplasm and light blue staining of the nuclei of all cells. In $B R: P e x 5^{-1-}$ mice $(F, H)$, the staining pattern of catalase is punctate in neural cells but diffusely cytosolic and nuclear in endothelial cells (EC). Scale bars: $A-D, 100 \mu \mathrm{m} ; E-H, 10 \mu \mathrm{m}$.

studies performed in Pex5 knock-out mice (Baes et al., 1997; Gressens et al., 2000), the density of BrdU-stained cells was measured in the ventricular zone, intermediate zone (prospective white matter), and neocortical plate and was used as an index of the severity of the neuronal migration disorder. To avoid regional and experimental variations in labeling, sections from the different experimental groups including comparable anatomic regions in the frontoparietal area were treated simultaneously. Counts of BrdU-positive cells were performed by hand, using a counting grid under a $40 \times$ magnification objective. The counts were performed by an observer blind to the different experimental groups in a sector measuring 500 $\mu \mathrm{m}$ in length in the coronal plane within the frontoparietal cerebral wall (see Fig. $6 F$ ). This sector was divided into a ventricular zone (average surface area, $0.03 \mathrm{~mm}^{2}$ ), an intermediate zone (prospective white matter; average surface area, $0.05 \mathrm{~mm}^{2}$ ), and a neocortical plate (average surface area, $0.1 \mathrm{~mm}^{2}$ ) (Takahashi et al., 1992). For each experimental group, cells were counted in 10 different fields (five brains from three different litters, two nonadjacent sections of the right hemisphere per brain). Both the intensely and the weakly labeled cells were counted. To further confirm these quantitative data on a larger sample, we performed extensive counts for the most important data set, which comprised BrdU-positive cells in the intermediate zone after injection of BrdU at E13.5. In this subset of analysis, cells were counted in 40 different fields (five brains from three different litters, eight nonadjacent sections of the right hemisphere per brain, each section being separated from the next one by a fixed $14 \mu \mathrm{m}$ distance; see supplementary material, available at www.jneurosci.org).

\section{Neural cell death analysis}

To document neocortical cell death, sections immediately adjacent to those used for BrdU staining were used for immunodetection of cleaved caspase 3 (rabbit polyclonal antibody; Cell Signaling, Beverly, MA) and for termina deoxynucleotidyl transferase-mediated biotinylated UTP nick end-labeling (TUNEL) staining (in situ cell death detection kit; Roche, Meylan, France). Cleaved caspase 3-labeled cells and TUNEL-labeled nuclei were counted in a 1 $\mathrm{mm}^{2}$ area in the neocortical plate at the level of the frontoparietal cerebral wall. For each exper-

antigen-binding sites were detected with a peroxidase-coupled biotinavidin system (rabbit ExtraVidin kit; Sigma, Munich, Germany) and visualized by histochemical staining for peroxidase using Novared (Vector Laboratories, Burlingame, CA) as a substrate. Nuclei were counterstained with hematoxylin.

\section{Neuronal migration analysis}

To quantify the defects of neuronal migration, pulse-chase experiments with 5',3'-bromo-2'-deoxyuridine (BrdU) were performed. Pregnant dams carrying transgenic and wild-type mice were injected intraperitoneally at E13.5 or E15.5 with $50 \mathrm{mg} / \mathrm{kg}$ BrdU (Sigma). Mothers were killed at E18.5 by decapitation; fetuses were removed; and brains were fixed by immersion fixation in $70 \%$ ethanol. After paraffin embedding, 7 $\mu \mathrm{m}$ sections were cut coronally and either stained with cresyl violet or used for immunohistochemical detection of BrdU (mouse monoclonal antibody; Becton Dickinson, San Jose, CA). On the basis of previous imental group, 10 different fields (five brains from three different litters, two nonadjacent sections of the right hemisphere per brain) were analyzed.

\section{Statistical analysis}

Quantitative data are expressed as mean \pm SEM for each treatment group. Results were compared using ANOVA with Bonferroni's multiple comparison of means test. Differences were considered statistically significant at $p<0.05$.

\section{Results}

Generation of transgenic mice with brain- or liver-selective expression of Pex5p

To reconstitute peroxisomes in fetal Pex5 knock-out mice in a tissue-selective way, transgenic mice were generated expressing 
myc-tagged Pex5p under the control of a tissue-selective promoter. The mycPex 5 fusion protein was able to restore the import of peroxisomal matrix proteins in $P e \times 5^{-1-}$ fibroblasts (data not shown). For the brain-selective reconstitution of Pex5p, the second intron of the nestin intermediate filament gene fused to the thymidine kinase minimal promoter was used (Zimmerman et al., 1994; Yamaguchi et al., 2000). This promoter restricts transgene expression to neuroepithelial cells that are precursors for the neuronal and glial lineage. The $7.6 \mathrm{~kb} 5$ ' flanking region of the $\alpha$-fetoprotein gene was used to overexpress Pex5p in hepatocytes (Godbout et al., 1986; Hammer et al., 1987; Potts et al., 2000) (Fig. $1 A, B)$. Pronuclear zygote injection yielded three and two founder mice that had inserted the nestin-mycPex5 and the AFP-mycPex 5 constructs, respectively. After crossbreeding with $P e x 5^{+/-}$mice, one of the AFP-mycPex 5 founders appeared to be infertile, and from one of the nestin-mycPex5 founders, no pups with the desired genotype were obtained. Further phenotypic analysis was performed on one mouse line expressing mycPex $5 p$ in liver (denoted LR:Pex5 mice) and on one of the two mouse lines expressing mycPex $5 p$ in brain (denoted BR:Pex5 mice).

\section{Characterization of transgenic mice with brain- or liver- selective expression of mycPex $5 p$}

As illustrated in Figures 2 and 3, the selectivity and functionality of transgene expression were evaluated in the relevant tissues of

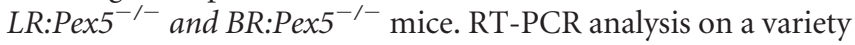
of tissues of E18.5 fetuses revealed that $m y c P e x 5$ cDNA was only demonstrable in brain and spinal cord of a $B R: P e \times 5^{-/-}$mouse and in liver and kidney of a $L R: P e \times 5^{-/-}$mouse, in correspondence with the promoter activity present in the constructs (Fig. $2 A, B)$. To assess the expression of the Pex 5 protein, immunoblotting and immunocytochemical experiments were performed. In BR:Pex $5^{-/-}$mice, mycPex5p was detectable in E14.5 brain homogenates and in E18.5 neocortex but was present at lower levels than the endogenous Pex5p in a wild-type mouse (Fig. 2C). In liver homogenates of $L R: P e x 5^{-/-}$mice, mycPex $5 \mathrm{p}$ was detectable at both E14.5 and E18.5 (Fig. 2D). As expected, no Pex5p immunoreactivity was observed in homogenates prepared from brain or liver of a generalized Pex5 knock-out mouse. In liver as well as brain, the transgene gave rise to the full-length Pex5 protein as well as to a shorter protein (Fig. 2C,D, arrowheads). Because this immunoreactive band was not detected with an antibody directed to the $\mathrm{N}$ terminus of Pex $5 \mathrm{p}$, we assume that this is a shorter Pex 5 product that is generated by using an alternative translation start site. These data were confirmed by strong immunocytochemical staining of Pex5p in all layers of the cortex of E14.5 $B R: P e x 5^{-/-}$mice whereas no staining was observed in knock-out animals (Fig. $3 A, B$ ). In E18.5 BR:Pex $5^{-/-}$mice, Pex5p staining was strongly reduced in the outer cortical layers but was still very intense in the germinative zone (Fig. 3D).

Subsequently, we examined whether MycPex5p expressed in the rescue mice was capable of restoring peroxisomal matrix im-
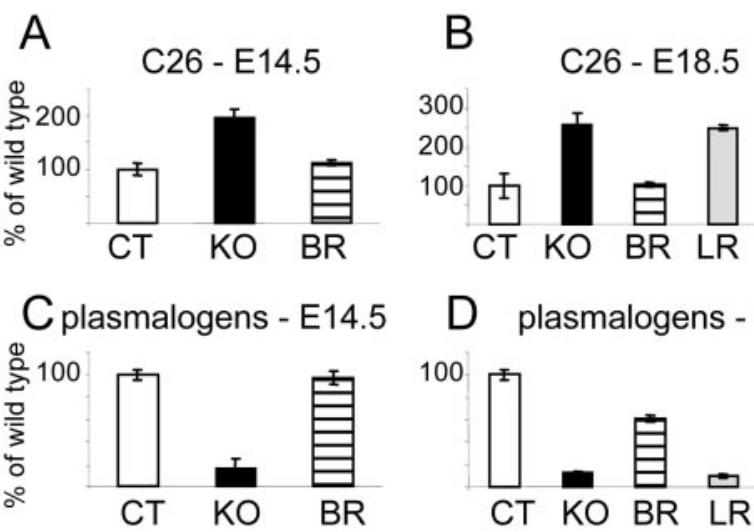

D plasmalogens - E18.5

100

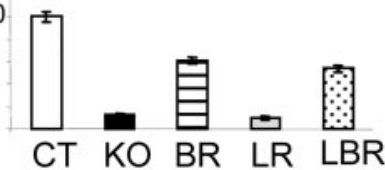

E

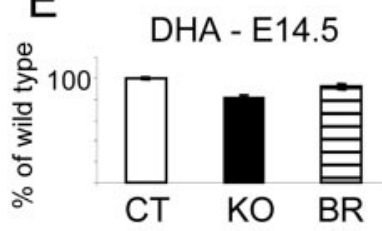

F

DHA - E18.5

100

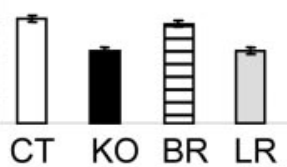

Figure 5. Peroxisomal metabolic parameters in brain of $B R: P e \times 5^{-/-}, L R: P e x 5^{-/-}$, and $L B R: P e x 5^{-1-}$ mice. The levels of C26:0, DHA, and plasmalogens were measured in brain of E14.5 control (CT), complete Pex5 knock-out (K0), and BR:Pex $5^{-1-}$ mice (left plots) and E18.5 control, complete knock-out, $B R: P e \times 5^{-1-}$, and $L R: P e \times 5^{-1-}$ mice (right plots). Plasmalogen levels were also measured in E18.5 LBR:Pex $5^{-/-}$mice. Values are expressed as percentages of levels in age-matched controls.

port. Therefore, the processing of acyl-CoA oxidase, a protein with a C-terminal peroxisomal-targeting signal 1 (PTS1), and peroxisomal 3-ketoacyl-CoA thiolase, a protein with an $\mathrm{N}$-terminal cleavable targeting signal 2 (PTS2), was monitored in liver and brain homogenates by Western blot analysis. It is indeed 

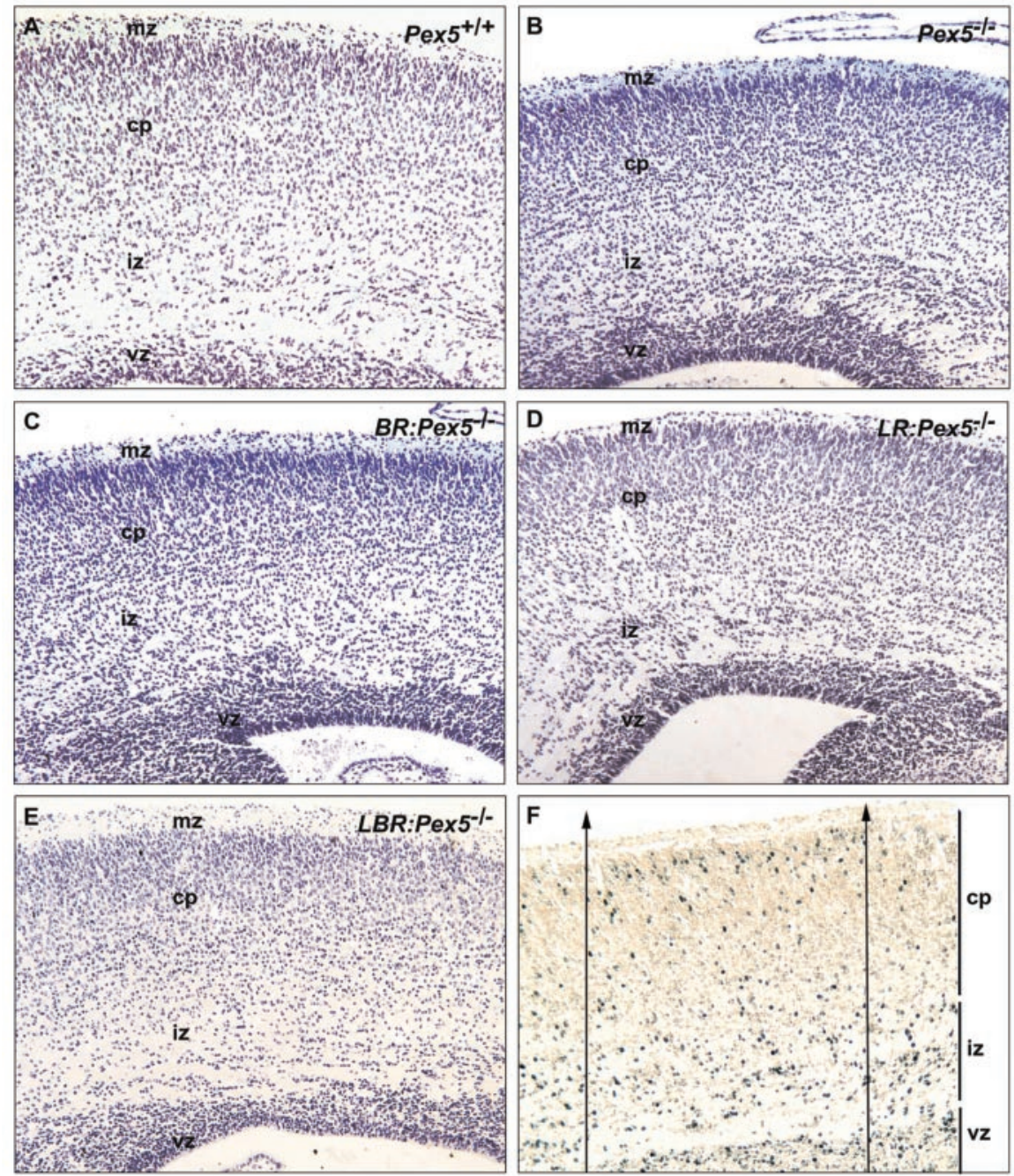

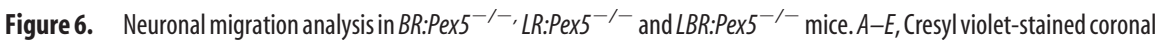
sections of E18.5 mice with the indicated genotypes. mz, Marginal zone; cp, cortical plate; iz, intermediate zone; vz, ventricular zone. F, Frontoparietal region of the murine cerebral wall at E18.5. Nuclei in S-phase are immunostained (dark deposit) with anti-BrdU antibody, and the tissue is counterstained with cresyl violet. BrdU ( $50 \mathrm{mg} / \mathrm{kg}$ ) was injected on E13.5. The $500-\mu \mathrm{m}$-wide sector on which the quantitative analyses are based is enclosed within the vertical arrows. Labeled nuclei were counted (see Fig. 7) within these two vertical lines, in the vz, iz, and cp.

known that the proteolytic cleavage of these enzymes depends on their import into peroxisomes. As shown in Figure 2, $E$ and $F$, the processed form of acyl-CoA oxidase was not detectable in liver or brain of generalized Pex 5 knock-out mice. In contrast, the $52 \mathrm{kDa}$ subunit of acyl-CoA oxidase was found in neocortex of E18.5 $B R: P e x 5^{-/-}$mice and in liver of E18.5 LR:Pex $5^{-/-}$mice, as also observed in the respective wild-type tissues. Similarly, 3-ketoacyl-CoA thiolase was processed in the target tissue of the rescue mice (data not shown), suggesting that the import of PTS1 and PTS2 proteins was restored in the two tissue-selective Pex5 rescue strains. In the kidney of $L R: P e x 5^{-/-}$mice, no processing of acyl-CoA oxidase was observed on Western blots, indicating that the Pex5 transcripts found in this organ were insufficient to generate functional Pex5 protein (data not shown).

Because the neuronal migration defects in Pex5 knock-out mice predominantly manifest between E14.5 and E18.5, it is crucial that peroxisomal function resumes in the targeted tissue before this stage. This was investigated by measuring the activity of dihydroxyacetonephosphate acyl transferase (DHAPAT), an enzyme of the ether phospholipid synthesis pathway, which is known to be inactive in Zellweger patient fibroblasts (Datta et al., 1984). DHAPAT activity was not detectable in liver or brain homogenates of the generalized Pex5 knock-out mice at E14.5 and at E18.5, confirming previous results (Baes et al., 1997). In liver of LR:Pex $5^{-/-}$mice, DHAPAT activity was restored to $30 \%$ of wild-type levels at both E14.5 and E18.5 (Fig. $2 H$ ). This is in good agreement with the partial restoration of plasmalogen levels $(6.4 \mathrm{pmol} / \mathrm{nmol}$ phospholipids in knock-out mice, $15.4 \mathrm{pmol} / \mathrm{nmol}$ in $L R$ : $P e \times 5^{-1-}$ mice, and $28.2 \mathrm{pmol} / \mathrm{nmol}$ in wild-type mice) and of urate oxidase activity $(25 \pm 4 \%$ of wild type activity in $L R$ : $P e x 5^{-1-}$ mice, not measurable in Pex5 knock-out mice). In brain of BR:Pex $5^{-/-}$ mice, DHAPAT activity was restored to $70 \%$ of wild-type levels at E14.5 but was decreased again to $50 \%$ of normal levels in brain of E18.5 pups (Fig. 2G).

To demonstrate the presence of structurally intact peroxisomes in the cortex of BR:Pex $5^{-1-}$ mice, immunocytochemical staining of the peroxisomal marker enzyme catalase was performed. As expected, a punctate fluorescence pattern was observed in all cell types of wild-type mice (Fig. 3E), and diffuse cytoplasmic staining was observed in both neural and

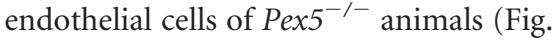
$3 G)$. In the absence of peroxisomes, catalase also resided in the nucleus, as previously observed (Baes et al., 1997). Importantly, in the cortex of E14.5 and E18.5 BR:Pex $5^{-/-}$mice (Fig. $3 F, H$ ), catalase immunoreactivity was found as a punctate pattern in all cells except endothelial cells. In comparison with wild-type mice, fewer peroxisomes were found in neural cells of E14.5 mice, and even fewer were found in E18.5 BR:Pex $5^{-/-}$mice (Fig. 3E,F,H). However, in the latter mice, no sign of cytosolic or nuclear localization of catalase was found in any of the cortical layers, indicating that even the diminished levels of Pex5p in the outer cortical layers were sufficient to allow import of peroxisomal proteins. In liver of three $L R: P e \times 5^{-/-}$mice, examined by electron microscopic analysis after cytochemical staining for catalase, structurally intact peroxisomes were found in a fraction of hepatocytes $(10-40 \%)$ but not in Kupffer or endothelial cells (Fig. 4C-E). Interestingly, in the hepatocytes lacking catalase-positive peroxisomes, mitochondria with abnormal cristae were found (Fig. $4 D, E$, asterisk) as previously observed in liver of generalized Pex5 knock-out mice (Baumgart et al., 2001).

\section{Phenotypic analysis of transgenic mice with brain- or liver- selective reconstitution of peroxisomes Macroscopic evaluation}

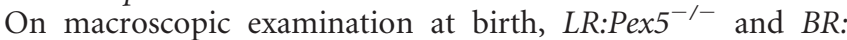
$P e \times 5^{-/-}$mice were indistinguishable from the generalized Pex5 knock-out mice (Baes et al., 1997), whereas they could easily be discriminated from wild-type littermates. They displayed intra- 
uterine growth retardation with an average $30 \%$ body weight reduction at birth compared with control littermates. Newborn LR:Pex $5^{-/-}, B R: P e x 5^{-/-}$, and generalized $P e x 5^{-/-}$pups were severely hypotonic, unable to support their body weight on their legs and to feed themselves, and they kept a contracted posture. Most died within $24 \mathrm{hr}$ after birth, and none survived $>48 \mathrm{hr}$. Double-rescue mice (LBR:Pex $5^{-/-}$), obtained by intercrossing $L R: P e x 5^{+/-}$and $B R$ : $P e x 5^{+/-}$mice, exhibited the same macroscopic phenotype and had the same life span as the single rescue or generalized Pex5 knock-out mice.

\section{Biochemical analysis}

In peroxisome deficiency disorders, the accumulation of VLCFA and the depletion of plasmalogens and C22:6n-3 have been hypothesized to be related to the neurodevelopmental disturbances. To correlate the levels of these compounds in

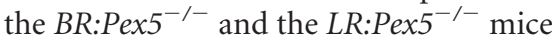
with the brain phenotype, their concentrations were determined in phospholipids extracted from whole brain of E14.5 and E18.5 fetuses.

In brain of E14.5 and E18.5 Pex5 $5^{-/-}$ fetuses, hexacosanoic acid (C26:0) levels were twofold to threefold elevated, in agreement with previous reports (Baes et al., 1997; Janssen et al., 2000). As shown in Figure 5, $A$ and $B$, the $\mathrm{C} 26: 0$ concentration was normalized in brain of BR:Pex $5^{-/-}$ mice at both fetal ages. Also, the concentration of DHA in brain, which was 30\% reduced in generalized Pex5 knock-out mice at E18.5 or birth (Janssen et al., 2000), was restored to wild-type values in BR:Pex $5^{-/-}$mice (Fig. 5E,F). Finally, the severe depletion of plasmalogens in brain of Pex5 $5^{-1-}$ mice was fully normalized in E14.5 BR:Pex5 ${ }^{-1-}$ fetuses (Fig. 5C). However, in brain of E18.5 BR:Pex $5^{-1-}$ pups (Fig. 5D), plasmalogen levels were only $60 \%$ of wild-type values, which is in agreement with the decline of DHAPAT activity in brain of BR:Pex5 $5^{-1-}$ mice at the end of gestation.

These peroxisomal metabolic parameters were also monitored in brain of mice with reconstituted peroxisomal function in liver. C26:0 levels were elevated and plasmalogens and C22:6n-3 were depleted to the same extent in brain of LR:Pex $5^{-/-}$mice (Fig. 5B,D,F) as in generalized Pex5 knock-out mice. In the double-rescue LBR:Pex $5^{-1-}$ mice, levels of plasmalogens in brain were comparable with the levels found in BR:Pex $5^{-1-}$ mice (Fig. 5D).

\section{Neocortical neuronal migration}

In agreement with previous reports, examination of cresyl violetstained coronal sections of E18.5 Pex5 ${ }^{-/-}$pups revealed altered cell densities in the cortical plate and white matter, consistent
BrdU E13.5
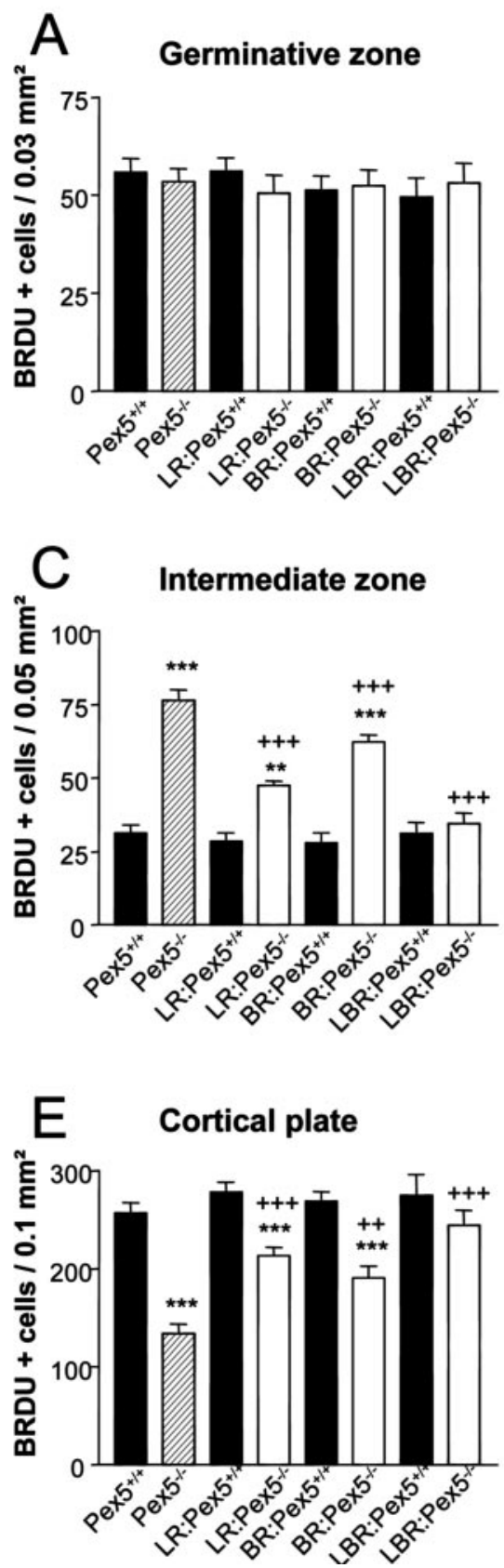

Figure 7. Quantitative analysis of BrdU-labeled cells in $B R: P e \times 5^{-/-}, L R: P e \times 5^{-/-}$, and $L B R: P e \times 5^{-/-}$mice. Counts of BrdUlabeled cells at E18.5 in the germinative zone, intermediate zone, and neocortical plate after injection of BrdU into pregnant animals at E13.5 or E15.5 are shown. The average counts \pm SEM of five different mice of each genotype are represented. Statistically significant differences from black bars $\left({ }^{*}\right)$ or hatched bars $\left({ }^{+}\right):{ }^{+} p<0.05 ;{ }^{* *},++p<0.01 ;{ }^{* * *,++}{ }^{++} p<0.001$, ANOVA with Bonferroni's multiple-comparison test.
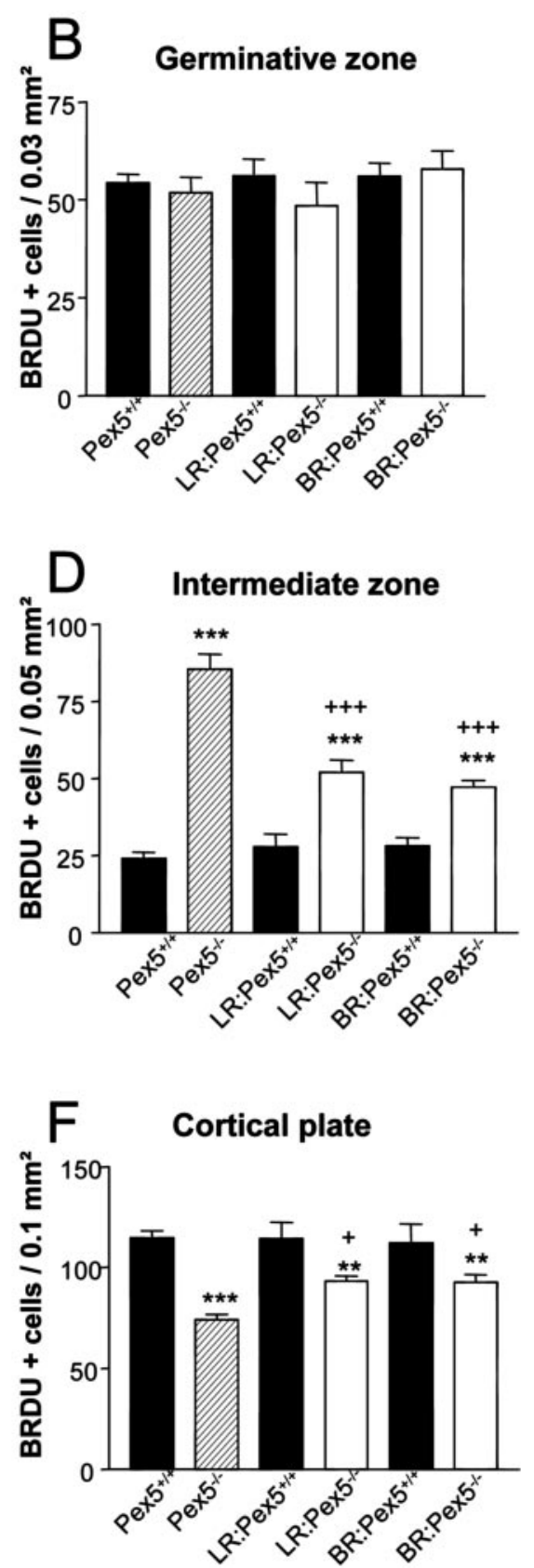

with a delay of neuronal migration (Fig. $6 A, B)$. Interestingly, in

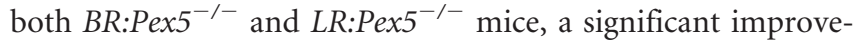
ment of the neuronal migration process was observed. In both cases, fewer neurons were located in the intermediate zone compared with Pex5 knock-out mice (Fig. 6C,D). Finally, in double-

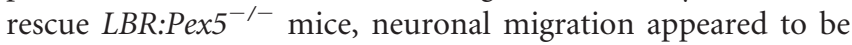
normalized because the density of cells in the intermediate zone in the double-rescue mice was indistinguishable from that in wild-type mice (Fig. 6E). 
To quantify the neuronal migration phenotype, BrdU pulsechase experiments were performed. Pregnant animals were given a single BrdU injection at E13.5 or at E15.5 of gestation, and the numbers of BrdU-labeled nuclei present in the germinative zone, intermediate zone, and neocortical plate were monitored at E18.5 (Fig. 6F). As shown in Figure 7, a 2.4-fold increase of BrdUlabeled nuclei was observed in the intermediate zone of Pex5 knock-out brains compared with wild-type littermates, whereas a $48 \%$ reduction of BrdU-labeled nuclei was observed in the neocortical plate (Fig. $7 E, F$ ), and no change was detectable in the germinative zone (Fig. 7A,B), confirming previous reports (Baes

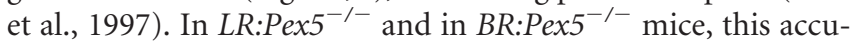
mulation in the intermediate zone was significantly reduced, with 1.8- and 1.4-fold more nuclei in the intermediate zone in comparison with wild-type mice (Fig. 7C,D). Similarly, the paucity of labeled cells in the neocortical plate was significantly improved in

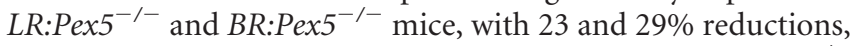
respectively (Fig. $7 E, F$ ). Finally, double-rescue $L B R: P e x 5^{-/-}$ mice exhibited BrdU counts that were not significantly different from wild-type values, in both the intermediate zone and neocortical plate (Fig. 7C,E). More extensive counts (eight instead of two sections per brain) of BrdU-positive cells in the intermediate zone yielded essentially the same results as the data reported above (see supplementary material, available at www.jneurosci. org). Only the slight difference between the BrdU counts in the intermediate zone of the LR versus the BR mice (Fig. 7C) became smaller, indicating that there is no important difference in restoration of the migration defect between the two rescue strains.

\section{Neocortical neural cell death}

Confirming previous results (Baes et al., 1997), increased neural cell death was found in the neocortical plate of Pex $5^{-/-}$mice when compared with wild-type animals using both immunodetection of cleaved caspase-3 (Fig. $8 A-E$ ) and TUNEL staining (Fig. $8 F$ ). In both $B R: P e x 5^{-/-}$and $L R: P e x 5^{-1-}$ mice, a significant reduction of neural cell death was observed (Fig. $8 E, F$ ). In double-rescue $L B R: P e \times 5^{-/-}$mice, cleaved caspase- 3 counts were close to wild-type values, whereas counts of TUNEL-labeled nuclei were greatly reduced when compared with $P e x 5^{-1-}$ mice but still significantly higher than in $P e x 5^{-/-}$mice (Fig. 8 E,F).

\section{Discussion}

Although the adverse effects of defective peroxisomal function on the formation of cortex, cerebellum, and inferior olivary nucleus have been well documented, the precise molecular mechanisms causing these morphogenic defects are still enigmatic. The observation that the neuronal migration impairment also occurs in peroxisome-deficient transgenic mice (Baes et al., 1997; Faust and Hatten, 1997) opened new possibilities to study the links between peroxisomal function and neuronal migration.

In the present study, we show that peroxisomal metabolism in brain as well as in extraneuronal tissues can influence the neuronal migration process in the mouse. In addition, by correlating peroxisomal metabolic parameters in brain to the migration phenotype, it seems unlikely that the accumulation of very long chain fatty acids, the depletion of plasmalogens, or the reduced content of DHA by themselves cause the migration defect in peroxisome deficiency disorders.

\section{Intact peroxisomal function in neuronal and extraneuronal} tissues is essential for normal neuronal migration

Both brain- and liver-selective reconstitution of peroxisomes in Pex5 knock-out mice resulted in a partial improvement of the

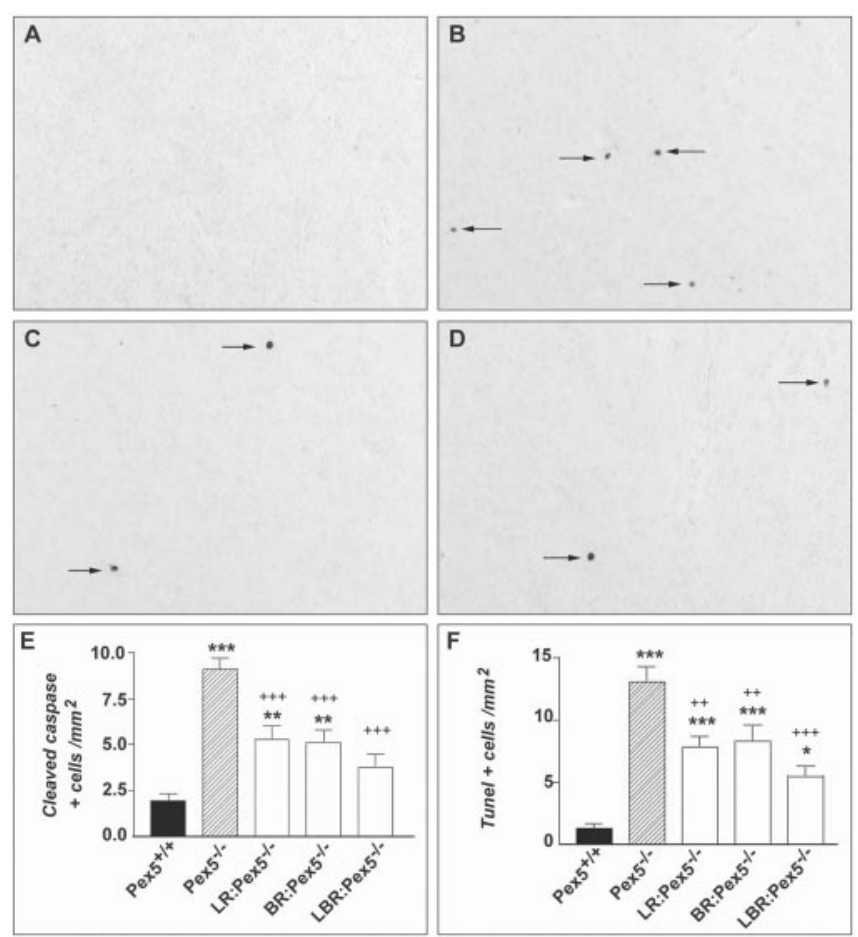

Figure 8. Cell death analysis in $B R: P e \times 5^{-1-}, L R: P e \times 5^{-1-}$ and $L B R: P e \times 5^{-1-}$ mice. Shown are caspase- 3 staining in wild-type $(A), \operatorname{Pex} 5$ knock-out $(B), B R: P e \times 5^{-1-}(C)$, and $L R: P e \times 5^{-1-}$ $(D)$ neocortex and counts of cleaved caspase-3-positive $(E)$ or TUNEL-labeled $(F)$ cells at E18.5 in the neocortical plate. Statistically significant differences from black bars $\left({ }^{*}\right)$ or hatched bars $\left({ }^{+}\right):{ }^{* *} p<0.01{ }^{* * *},+++p<0.001$, ANOVA with Bonferroni's multiple-comparison test.

neuronal migration process in comparison with the defect observed in generalized Pex5 knock-out mice. Concomitantly, the neural cell death was less severe in the two rescue strains than in the Pex5 knock-out mice.

In the Pex5 brain rescue strain, the reconstitution of peroxisomes appeared to be virtually complete during the critical period of neuronal migration, as shown by the presence of catalasepositive peroxisomes, the import of peroxisomal enzymes, and normalized levels of DHA and C26:0, at both E14.5 and E18.5. Plasmalogen content was completely restored in the brain at E14.5 but was again reduced to $60 \%$ of normal levels at E18.5, coincident with the lower activity of DHAPAT in E18.5 compared with E14.5 pups. Although we do not have a clear-cut explanation for this decline, it may be related to the temporary activity of the nestin enhancer, which is known to be switched off in postmitotic neurons (Zimmerman et al., 1994). As a result, mycPex $5 p$ levels may be lower in certain areas of the brain in the prenatal period. This did not seem to affect the function of peroxisomal $\beta$ oxidation but might have been limiting for the import of ether phospholipid-synthesizing enzymes. Immunocytochemical analysis of catalase in the cortex of E18.5 pups confirmed that peroxisomes were still present in the different cortical layers at that age.

Taken together, we cannot exclude the possibility that the partial restoration of neuronal migration in the $B R: P e \times 5^{-1-}$ mice is attributable to the incomplete reconstitution of peroxisomal function in the prenatal period. However, we favor the possibility that normal cortical development depends on functional peroxisomes in other organs as well. This idea was corroborated by the finding that a significant improvement of neuronal migration was observed in Pex5 liver rescue mice, even though the restora- 
tion of peroxisomal function in liver was only 30\%. In addition, simultaneous peroxisomal reconstitution in both liver and brain resulted in a pattern of neuronal migration indistinguishable from that of wild-type mice with the currently used techniques and a level of apoptotic neural cell death intermediate between $B R: P e x 5^{-/-}$and wild-type mice.

The partial restoration of peroxisomal function in liver of $L R: P e \times 5^{-/-}$mice raises the question of whether complete restoration of hepatic peroxisomal function might normalize neuronal migration. An additional question is whether the impact of liver peroxisomes on brain development is specific for hepatocytes or whether it could also be exerted by peroxisomes in other tissues. Such questions might be resolved by generating mice with liver- and brain-selective depletion of peroxisomes using Pex5loxP mice (Baes et al., 2002a) and appropriate Cre-expressing mice.

\section{Pathogenic factors causing the neuronal migration defect in peroxisome deficiency disorders}

Increased levels of VLCFA have often been considered as the cause of the neuronal migration defect in Zellweger patients (Moser and Moser, 1996). The availability of transgenic mouse models allows the analysis of neuronal migration in concert with the measurement of VLCFA levels in brain. An important improvement of the neuronal migration process was observed in Pex5 liver rescue mice despite the fact that in brain, C26:0 was accumulating to the same extent as in the Pex5-deficient mice. Conversely, normalization of the C26:0 levels in brain of brain rescue mice did not lead to a full restoration of neuronal migration. These data do not support a role for VLCFA as the single cause of the neuronal migration defect in peroxisome deficiency and are in line with results in other mouse models. Indeed, abnormalities in the cortical lamination were seen in Pex $11 \beta$ knockout mice, which exhibit only minor changes in brain C26:0 levels (Li et al., 2002). On the other hand, in mice with selective peroxisomal $\beta$ oxidation defects (acyl-CoA oxidase and X-linked adrenoleukodystrophy knock-out mice), C26:0 accumulations were found in brain, but no neurodevelopmental abnormalities were reported (Fan et al., 1996; Forss-Petter et al., 1997; Kobayashi et al., 1997; Lu et al., 1997). Furthermore, in MFP-2 knock-out mice, which accumulate $\mathrm{C} 26: 0$ in brain to the same extent as Pex5 knock-out mice at the time of birth, no signs of disturbed neuronal migration were found by using the same brain analysis procedures as for the Pex5 knock-out mice (Baes et al., 2002b). Thus, on the basis of the present and earlier experimental evidence, it seems unlikely that the excess of VLCFA on its own causes the neuronal migration defect in Pex5 knock-out mice, although it cannot be excluded that it is a contributing factor.

In the brain of liver-rescued mice, besides the high levels of C26:0, a depletion of plasmalogens and a reduction of C22:6n-3 were also found. Therefore, the significant improvement of the neuronal migration defect in these mice seems to be mediated by the correction of other metabolic factors. After a landmark analysis of a Zellweger brain, Evrard et al. (1978) speculated that there is some type of toxic insult to both migrating neurons and radial glial cells. Increased levels of a neurotoxic compound are indeed among the likely pathogenic mechanisms that fit well with the beneficial role of hepatic peroxisomes on brain development documented in this study.

We do not know which metabolic factors underlie the improved neuronal migration after local restoration of peroxisomal function in brain. Given the corrected levels of C26:0, the improved levels of plasmalogens, and the normalization of $\mathrm{C} 22$ :
$6 \mathrm{n}-3$, it is possible that a combination of these and potentially other factors could be involved.

In conclusion, the present findings are consistent with the notion that multiple metabolic disturbances are etiological to the migration disturbance in conditions of peroxisome deficiency. To further decipher the role of peroxisomes in the neuronal migration process, it will be necessary to conduct a more extensive metabolic investigation of the affected brain and to document possible alterations in the signaling molecules that are starting to be uncovered as key players in the control of the neuronal migration process.

\section{References}

Antonenkov VD, Van Veldhoven PP, Waelkens E, Mannaerts GP (1997) Substrate specificities of 3-oxoacyl-CoA thiolase A and sterol carrier protein 2/3-oxoacyl-CoA thiolase purified from normal rat liver peroxisomes. J Biol Chem 272:26023-26031.

Baes M, Gressens P, Baumgart E, Carmeliet P, Casteels M, Fransen M, Evrard P, Fahimi D, Declercq PE, Collen D, Van Veldhoven PP, Mannaerts GP (1997) A mouse model for Zellweger syndrome. Nat Genet 17:49-57.

Baes M, Dewerchin M, Janssen A, Collen D, Carmeliet P (2002a) Generation of Pex5-IoxP mice allowing the conditional elimination of peroxisomes. Genesis 32:177-178.

Baes M, Gressens P, Huyghe S, De Nys K, Qi C, Jia Y, Mannaerts GP, Evrard P, Van Veldhoven PP, Declercq PE, Reddy JK (2002b) The neuronal migration defect in mice with Zellweger syndrome (Pex5 knockout) is not caused by the inactivity of peroxisomal $\beta$-oxidation. J Neuropathol Exp Neurol 61:368-374.

Baumgart E, Völkl A, Hashimoto T, Fahimi HD (1989) Biogenesis of peroxisomes: immunocytochemical investigation of peroxisomal membrane proteins in proliferating rat liver peroxisomes and in catalase-negative membrane loops. J Cell Biol 108:2221-2231.

Baumgart E, Vanhorebeek I, Grabenbauer M, Borgers M, Declercq P, Fahimi HD, Baes M (2001) Mitochondrial alterations caused by defective peroxisomal biogenesis in a mouse model for Zellweger syndrome (PEX5 knockout mouse). Am J Pathol 159:1477-1494.

Behar TN, Li Y-X, Tran HT, Ma W, Dunlap V, Scott C, Barker JL (1996) GABA stimulates chemotaxis and chemokinesis of embryonic cortical neurons via calcium-dependent mechanisms. J Neurosci 16:1808-1818.

Datta NS, Wilson GN, Hajra AK (1984) Deficiency of enzymes catalyzing the biosynthesis of glycerol-ether lipids in Zellweger syndrome. N Engl J Med 311:1080-1083.

Evrard P, Caviness VS, Prats-Vinas J, Lyon G (1978) The mechanism of arrest of neuronal migration in the Zellweger malformation: an hypothesis based upon cytoarchitectonic analysis. Acta Neuropathol (Berl) 41:109-117.

Fahimi HD (1969) Cytochemical localization of peroxidatic activity of catalase in rat hepatic microbodies (peroxisomes). J Cell Biol 43:275-288.

Fan C-Y, Pan J, Chu R, Lee D, Kluckman KD, Usuda N, Singh I, Yeldandi AV, Rao MS, Maeda N, Reddy JK (1996) Hepatocellular and hepatic peroxisomal alterations in mice with a disrupted peroxisomal fatty acylcoenzyme A oxidase gene. J Biol Chem 271:24698-24710.

Faust PL, Hatten ME (1997) Targeted deletion of the PEX2 peroxisome assembly gene in mice provides a model for Zellweger syndrome, a human neuronal migration disorder. J Cell Biol 139:1293-1305.

Fleenor DE, Kaufman RE (1993) Characterization of the DNase I hypersensitive site $3^{\prime}$ of the human $\beta$ globin gene domain. Blood 81:2781-2790.

Forss-Petter S, Werner H, Berger J, Lassmann H, Molzer B, Schwab MH, Bernheimer H, Zimmermann F, Nave K-A (1997) Targeted inactivation of the X-linked adrenoleukodystrophy gene in mice. J Neurosci Res 50:829-843.

Godbout R, Ingram R, Tilghman SM (1986) Multiple regulatory elements in the intergenic region between the $\alpha$-fetoprotein and albumin genes. Mol Cell Biol 6:477-487.

Gould SJ, Raymond GV, Valle D (2001) The peroxisome biogenesis disorders. In: The metabolic and molecular bases of inherited disease (Scriver CR, Beaudet AL, Valle D, Sly WS, eds), pp 3181-3217. New York: McGraw-Hill.

Grabenbauer M, Fahimi HD, Baumgart E (2001) Detection of peroxisomal proteins and their mRNAs in serial sections of fetal and newborn mouse organs. J Histochem Cytochem 49:155-164. 
Gressens P (2000) Mechanisms and disturbances of neuronal migration. Pediatr Res 48:725-730.

Gressens P, Baes M, Leroux P, Lombet A, Van Veldhoven P, Janssen A, Vamecq J, Marret S, Evrard P (2000) Neuronal migration disorder in Zellweger mice is secondary to glutamate receptor dysfunction. Ann Neurol 48:336-343.

Hammer RE, Krumlauf R, Camper SA, Brinster RL, Tilghman SM (1987) Diversity of alpha-fetoprotein gene expression in mice is generated by a combination of separate enhancer elements. Science 235:53-58.

Hatten ME (1999) Central nervous system neuronal migration. Annu Rev Neurosci 22:511-539.

Huyghe S, Casteels M, Janssen A, Meulders L, Mannaerts GP, Declercq PE, Van Veldhoven PP, Baes M (2001) Prenatal and postnatal development of peroxisomal lipid-metabolizing pathways in the mouse. Biochem J 353:673-680.

Janssen A, Baes M, Gressens P, Mannaerts GP, Declercq P, Van Veldhoven PP (2000) Docosahexaenoic acid deficit is not a major pathogenic factor in peroxisome-deficient mice. Lab Invest 80:31-35.

Jones KM, Hajra AK (1994) Assay of dihydroxyacetone phosphate acyltransferase with ${ }^{32} \mathrm{P}$-labeled substrate. Clin Chem 40:946-947.

Kobayashi T, Shinnoh N, Kondo A, Yamada T (1997) Adrenoleukodystrophy protein-deficient mice represent abnormality of very long chain fatty acid metabolism. Biochem Biophys Res Commun 232:631-636.

Komuro H, Rakic P (1992) Selective role of N-type calcium channels in neuronal migration. Science 257:806-809.

Li X, Baumgart E, Morrell JC, Jimenez-Sanchez G, Valle D, Gould SJ (2002) PEX11 $\beta$ deficiency is lethal and impairs neuronal migration but does not abrogate peroxisome function. Mol Cell Biol 22:4358-4365.

Lu J-F, Lawler AM, Watkins PA, Powers JM, Moser AB, Moser HW, Smith KD (1997) A mouse model for X-linked adrenoleukodystrophy. Proc Natl Acad Sci USA 94:9366-9371.

Moser HW, Moser AB (1996) Very long-chain fatty acids in diagnosis, pathogenesis, and therapy of peroxisomal disorders. Lipids 31:141-144.
Pikaart MJ, Recillas-Targa F, Felsenfeld G (1998) Loss of transcriptional activity of a transgene is accompanied by DNA methylation and histone deacetylation and is prevented by insulators. Genes Dev 12:2852-2862.

Potts W, Tucker D, Wood H, Martin C (2000) Chicken $\beta$-globin 5'HS4 insulators function to reduce variability in transgenic founder mice. Biochem Biophys Res Commun 273:1015-1018.

Powers JM (1995) The pathology of peroxisomal disorders with pathogenic considerations. J Neuropath Exp Neurol 54:710-719.

Purdue PE, Lazarow PB (2001) Peroxisome biogenesis. Annu Rev Cell Dev Biol 17:701-752.

Rakic P, Cameron RS, Komuro H (1994) Recognition, adhesion, transmembrane signaling and cell motility in guided neuronal migration. Neurobiology 4:63-69.

Subramani S, Koller A, Snyder WB (2000) Import of peroxisomal matrix and membrane proteins. Annu Rev Biochem 69:399-418.

Takahashi T, Nowakowski RS, Caviness VS (1992) BrdU as an S-phase marker for quantitative studies of cytokinetic behaviour in the murine cerebral ventricular zone. J Neurocytol 21:185-197.

Terlecky SR, Fransen M (2000) How peroxisomes arise. Traffic 1:465-473,

Van Veldhoven PP, Van Rompuy P, Fransen M, de Béthune B, Mannaerts GP (1994) Large-scale purification and further characterization of ratpristanoyl-CoA oxidase. Eur J Biochem 222:795-801.

Walsh CA (1999) Genetic malformations of the human cerebral cortex. Neuron 23:19-29.

Yamaguchi M, Saito H, Suzuki M, Mori K (2000) Visualization of neurogenesis in the central nervous system using nestin promoter-GFP transgenic mice. Dev Neurosci 11:1991-1996.

Zimmerman L, Lendahl U, Cunningham M, McKay R, Parr B, Gavin B, Mann J, Vassileva G, McMahon A (1994) Independent regulatory elements in the nestin gene direct transgene expression to neural stem cells or muscle precursors. Neuron 12:11-24. 